\title{
OS DIREITOS HUMANOS DA MULHER TRABALHADORA IMIGRANTE REFUGIADA NO BRASIL SOB A PERSPECTIVA DAS EMPRESAS TRANSNACIONAIS.
}

\section{Rodrigo de Grandis ${ }^{1}$ Rodrigo Arantes Cavalcante ${ }^{2}$}

\begin{abstract}
Resumo: O presente artigo visa abordar a ligação entre trabalho, economia e as empresas transnacionais frente à absorção da força de trabalho das mulheres refugiadas como meio efetivador dos direitos humanos, bem como trazer a discussão quanto ao existente tráfico de mulheres refugiadas no exercício de trabalhos degradantes ou análogo à escravo. Ainda, ante a concentração de poder econômico das empresas transnacionais, bem como devido a sua projeção internacional como influenciadora de condutas se faz necessário elucidar se referidas empresas cumprem sua função social no Brasil quanto às mulheres refugiadas nas relações de trabalho.
\end{abstract}

Palavras-chave: direitos humanos; trabalhadoras; refugiadas; tráfico de pessoas; transnacionais.

\section{THE HUMAN RIGHTS OF IMMIGRATE REFUGEE WORKING WOMEN IN BRAZIL FROM THE PERSPECTIVE OF TRANSNATIONAL COMPANIES.}

\begin{abstract}
This article aims to address the link between work, economy and transnational corporations facing the absorption of the labor force of refugee women as a means of effecting human rights, as well as to discuss the existing trafficking of refugee women in the

\footnotetext{
${ }^{1}$ Doutor e Mestre em Direito Penal pela Faculdade de Direito da Universidade de São Paulo. Especialização em Direito Penal pela Universidad de Salamanca-Espanha. Professor da Faculdade de Direito da Fundação Getúlio Vargas (Mestrado Profissional e da Especialização em Direito Penal Econômico e Compliance-FGVLAW), do curso de Mestrado e Doutorado da Uninove, do Mestrado Profissional do Instituto Brasiliense de Direito Público (IDP) e da Escola Superior do Ministério Público da União (ESMPU). Procurador da República (Ministério Público Federal) desde 2004, com atuação preponderante em crimes contra o sistema financeiro nacional e lavagem de ativos ilícitos. Membro do grupo de combate a cartéis da Procuradoria da República de São Paulo e do Grupo de Trabalho de Colaboração Premiada e Leniência da $5^{\text {a }}$ Câmara de Coordenação e Revisão do Ministério Público Federal. Foi Promotor de Justiça (Ministério Público do Estado de São Paulo) em 2003. A ênfase da sua produção acadêmica está voltada para as áreas de Direito Penal, Direito Penal Econômico, Direito Processual Penal, desenvolvendo pesquisas em torno dos temas de Imputação Penal, Responsabilidade Penal em estruturas organizadas, Infidelidade Patrimonial e Colaboração Premiada. rodrigograndis@mpf.mp.br
}

${ }^{2}$ Advogado, Mestrando em direito, Palestrante e Escritor. Advogado e Sócio do Escritório Do Val \& Cavalcante Sociedade de Advogados. Pós-graduado em Direito do Trabalho e Processo do Trabalho; Pós-Graduado em Direito Público: Tributário. Pós Graduado em Direito Médico e da Saúde. Autor das obras O Vínculo de emprego dos corretores de imóveis. $2^{\mathrm{a}}$ Ed. LTr; Manual de Iniciação do Advogado Trabalhista. $5^{\mathrm{a}}$ Edição. Ed. LTr; Reforma Trabalhista Comentada Artigo por Artigo. $2^{\text {a }}$ Edição . Ed. LTr; Audiência Trabalhista - Teoria e Prática. $2^{\mathrm{a}}$ edição. Editora Jh. Mizuno. Direito Médico e da Saúde - Manual Prático. Ed.JH. Mizuno. Membro efetivo da Comissão Especial de Direito Material do Trabalho da OABSP (2016/2018) e triênio (2019/2021). Membro efetivo da Comissão Especial de Direito Material do Trabalho da OABSP Tatuapé (2019/2021). Membro efetivo da Comissão Especial de Direito à Adoção OABSP (2016/2018). Rodrigo_arantescavalcante@yahoo.com.br 
exercise of work degrading or slave-like. Still, given the concentration of economic power of transnational companies, as well as due to their international projection as an influencer of behavior, it is necessary to elucidate whether these companies fulfill their social function in Brazil regarding refugee women in labor relations.

Keywords: human rights; female workers; refugees; trafficking in persons; transnational corporations.

\section{INTRODUÇÃO}

A globalização mudou a forma do mundo se comunicar, a cultura, a política e a economia mundial, com ela também se tem acesso de forma instantânea ao que ocorre em outro local do globo inclusive as causas de refúgio. O refúgio principalmente causado por conflitos armados e políticos vem ocasionando a saída do país de origem de milhares de pessoas, em especial mulheres e crianças.

O Brasil acolhe atualmente milhares de refugiados muitos adentram ao território nacional de forma legalizada e outros tantos não, mas todas essas pessoas que vivem em território nacional, em especial as mulheres merecem de fato ser acolhidas e ter os direitos humanos preservados. Logo, isso importa em dar efetivação aos direitos humanos dessa parcela da população, até mesmo porque o Brasil é um Estado Democrático de Direito que visa assegurar o exercício dos direitos sociais e individuais, a liberdade, a segurança, o bemestar, o desenvolvimento, a igualdade e a justiça como valores supremos de uma sociedade fraterna, pluralista e sem preconceitos, como consta do preâmbulo de nossa Constituição Federal.

Logo, as mulheres refugiadas no Brasil necessitam encontrar em solo brasileiro as mesmas condições que as nacionais no campo de garantia de direitos humanos, em especial de direitos sociais do trabalho. Outrossim, é dado destaque as mulheres tendo em vista que são estas o maior número de refugiadas no país ${ }^{3}$.

\footnotetext{
${ }^{3}$ Quanto ao gênero, o relatório apresentado pelo IMDH, observando que aqui se trata somente do atendimento a pessoas em situação de refúgio, demonstra que a proporção de mulheres segue aumentando desde 2017, alcançando $49 \%$ da população atendida. Esta tendência se explica primeiramente pelo crescente número de mulheres que encabeçam o projeto migratório e são chefes de família, bem como devido ao processo de reunião
} 
Para tanto há nítida relação entre a economia e a globalização não apenas quanto às causas do refúgio e o trânsito de pessoas entre os países, como também de modo interno no Brasil quanto à necessidade de existir uma economia forte e lastreada pelos direitos humanos para absorver pessoas de nacionalidades diversas que encontraram crise humanitária no solo de seus países.

No mais, com a pandemia da COVID-19 ficou ainda mais claro que, os acontecimentos em outros países a todos nós interessa, ficando ainda mais visível o fenômeno da Globalização e os efeitos que uma pandemia pode como de fato acarretou na economia como um todo.

Neste cenário de um "novo normal", com diversas empresas em grave crise econômica não só no Brasil como em diversos países, houve aumento do desemprego, além de outros acontecimentos que temos presenciado na mídia que contribuem para tal fato, como, por exemplo, uma multidão de pessoas que invadiram o aeroporto de $\mathrm{Cabul}^{4}$ para tentar embarcar em aviões no objetivo de deixar o Afeganistão, atualmente dominado pelo Talibã.

Assim, aliado a crise da Pandemia ainda temos a questão humanitária dos refugiados que no Brasil encontramos de diversas nacionalidades, e atualmente o Brasil avalia receber afegãos em programa de vistos rápidos a refugiados ${ }^{5}$ que seriam vistos humanitários assim como existe para facilitar a entrada de sírios e haitianos no país.

Portanto, o fenômeno da globalização e economia está cada vez mais presente na atualidade, não podendo a soberania ser analisada como antigamente, já que na atualidade temos uma economia de mercado, e os problemas de outros países são também nossos sendo que o lado humanitário deve ser sempre levado em consideração seja pelas autoridades políticas como também de todos os operadores do Direito.

Dessa forma, se torna urgente a discussão objetivo deste trabalho sobre a inserção das mulheres refugiadas no mercado de trabalho brasileiro, em especial, nas empresas transnacionais em igualdade de condições com os trabalhadores nacionais como meio de

familiar. https://www.migrante.org.br/projetos/relatorio-do-imdh-aponta-crescimento-do-numero-de-mulheresrefugiadas/

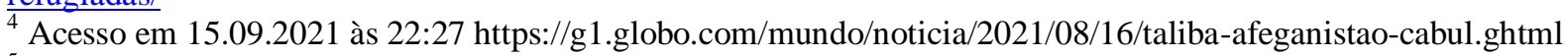

${ }^{5}$ Acesso em 15.09.2021 às 22:34 https://www.bbc.com/portuguese/internacional-58267914 
efetivar os direitos humanos, isso porque devemos aplicar a fraternidade prevista em nossa Constituição em conjunto com a livre iniciativa. E, nesse contexto, encontram-se os problemas a serem examinados no presente artigo.

Para tanto, dividiu-se o presente trabalho em quatro itens composto por esta breve introdução; o item dois tratando dos direitos humanos e as relações de trabalho das imigrantes refugiadas; o item três versando sobre o tráfico de Pessoas e as trabalhadoras refugiadas; o item quatro abrangendo a função social das transnacionais na inclusão das refugiadas no mercado de trabalho; e por fim as considerações finais.

A metodologia utilizada nesse trabalho parte dos métodos: dedutivo e indutivo, realizando a revisão da bibliografia apontada nas referências.

\section{DIREITOS HUMANOS E AS RELAÇÕES DE TRABALHO DAS IMIGRANTES REFUGIADAS.}

O refúgio das mulheres é uma das formas de preservação e garantias dos direitos humanos destas, em especial o direito à liberdade e segurança. Contudo, não podemos pensar que apenas o fato de outro país acolher as mulheres como refugiadas em seu solo é mecanismo efetivo para sua proteção e efetivação de direitos.

Logo, para que haja de fato a garantia aos direitos humanos das mulheres refugiadas se faz necessária a concretização do preceito insculpido no artigo $1^{\circ}$, incisos III e IV da Constituição Federal, isto constituindo a dignidade da pessoa humana e os valores sociais do trabalho como princípios fundamentais.

Os direitos de terceira geração ou dimensão consistem na busca pela fraternidade e solidariedade sendo, que no próprio Preâmbulo ${ }^{6}$ da Constituição Federal de 1988 observamos que o constituinte além de instituir o Estado Democrático, buscou assegurar o exercício dos

6 Nós, representantes do povo brasileiro, reunidos em Assembléia Nacional Constituinte para instituir um Estado Democrático, destinado a assegurar o exercício dos direitos sociais e individuais, a liberdade, a segurança, o bem-estar, o desenvolvimento, a igualdade e a justiça como valores supremos de uma sociedade fraterna, pluralista e sem preconceitos, fundada na harmonia social e comprometida, na ordem interna e internacional, com a solução pacífica das controvérsias, promulgamos, sob a proteção de Deus, a seguinte CONSTITUIÇÃO DA REPÚBLICA FEDERATIVA DO BRASIL. 
direitos sociais e individuais, além do bem-estar, o desenvolvimento, a igualdade e a justiça, fundamentando o constituindo que estes valores seriam supremos utilizando o termo: "sociedade fraterna, pluralista e sem preconceitos", comprometida tanto com a ordem interna como internacional, sendo importante observarmos o preâmbulo de nossa Constituição neste momento de pandemia e de exploração do trabalho do imigrante.

Outra norma constitucional aplicável para que os direitos das mulheres imigrantes sejam respeitados vem a ser o art. $3^{\circ}$, inciso I, III e $\mathrm{IV}^{7}$, isto porque constituem entre os objetivos fundamentais da República Federativa do Brasil construir uma sociedade livre, justa e solidária e não há nada mais solidário do que receber nossos irmãos imigrantes dando a eles não só a permissão de adentrarem em nosso país, mas também conceder condições dignas de trabalho, contribuindo com a erradicação da pobreza e a marginalização e reduzindo as desigualdades sociais e regionais.

Nota-se que o art. 3º inciso IV da Constituição Federal de 1988 dispõe ser objetivo fundamental da República Federativa do Brasil promover o bem de todos, sem preconceito de origem, raça, sexo, cor, idade ou quaisquer outras formas de discriminação, assim por bem de todos é óbvio que a Constituição tratou também da mulher imigrante, tema do nosso artigo.

A Constituição Federal de 1988 é, portanto conhecida como Constituição Cidadã por se preocupar com esses valores, sendo claro que os direitos de terceira geração são contemplados em nossa carta, tanto que o art. $4^{\circ}$ da Constituição Federal $^{8}$ ao tratar dos

\footnotetext{
7 Art. $3^{\circ}$ Constituem objetivos fundamentais da República Federativa do Brasil:

I - construir uma sociedade livre, justa e solidária;

II - garantir o desenvolvimento nacional;

III - erradicar a pobreza e a marginalização e reduzir as desigualdades sociais e regionais;

IV - promover o bem de todos, sem preconceitos de origem, raça, sexo, cor, idade e quaisquer outras formas de discriminação.

${ }^{8}$ Art. $4^{\circ}$ A República Federativa do Brasil rege-se nas suas relações internacionais pelos seguintes princípios:

I - independência nacional;

II - prevalência dos direitos humanos;

III - autodeterminação dos povos;

IV - não-intervenção;

$\mathrm{V}$ - igualdade entre os Estados;

VI - defesa da paz;

VII - solução pacífica dos conflitos;

VIII - repúdio ao terrorismo e ao racismo;

IX - cooperação entre os povos para o progresso da humanidade;

$\mathrm{X}$ - concessão de asilo político.
} 
princípios que regem as relações internacionais traz no inciso II o princípio da prevalência dos Direitos Humanos, no inciso VI o princípio da defesa da paz; no inciso VII trata sobre a solução pacífica de conflitos e no inciso VIII trata do princípio ao repúdio a terrorismo e ao racismo, sendo que no inciso IX mais uma vez realça o objetivo de solidariedade e fraternidade ao tratar como princípio a cooperação entre os povos para o progresso da humanidade.

$\mathrm{O}$ art. $5^{\circ}$ da Constituição Federal $^{9}$ ao tratar sobre os Direitos e Garantias Fundamentais, dispõe que todos são iguais perante a lei, não fazendo a Constituição qualquer distinção entre os brasileiros e aos estrangeiros residentes no País, sendo que no inciso $\mathrm{I}^{10}$ dispõe sobre a igualdade entre homens e mulheres.

Outro inciso da Constituição Federal, muito importante para o nosso estudo, vem a ser o inciso III do art. $5^{\circ}$ da Constituição Federal ${ }^{11}$, isto porque proíbe que alguém seja submetido à tortura ou a tratamento desumano ou degradante, como infelizmente ainda observamos em nossa sociedade e em trabalhos de mulheres imigrantes que por vezes são submetidas a trabalhos até mesmo análogos a escravidão.

No que tange ao trabalho da mulher imigrante, a mesma está amparada pela legislação trabalhista como também pela norma constitucional como o art. $7^{\circ}$ que em seu caput $^{12}$ traz o princípio da proibição ao retrocesso contemplando o direito de todos os trabalhadores, tanto que utiliza a expressão "além de outros" que visam à melhoria de sua condição social, sendo que o inciso XX do mesmo dispositivo dispõe sobre a proteção do mercado de trabalho da mulher, mediante incentivos específicos, nos termos da lei.

Parágrafo único. A República Federativa do Brasil buscará a integração econômica, política, social e cultural dos povos da América Latina, visando à formação de uma comunidade latino-americana de nações.

${ }^{9}$ Art. $5^{\circ}$ Todos são iguais perante a lei, sem distinção de qualquer natureza, garantindo-se aos brasileiros e aos estrangeiros residentes no País a inviolabilidade do direito à vida, à liberdade, à igualdade, à segurança e à propriedade, nos termos seguintes:

${ }_{11}^{10}$ I - homens e mulheres são iguais em direitos e obrigações, nos termos desta Constituição;

${ }^{11}$ III - ninguém será submetido a tortura nem a tratamento desumano ou degradante;

${ }^{12}$ Art. $7^{\circ}$ São direitos dos trabalhadores urbanos e rurais, além de outros que visem à melhoria de sua condição social: 
Nota-se por fim que a Constituição Federal até mesmo ao tratar da ordem econômica se preocupou com os valores sociais do trabalho tanto que no art. $170^{13}$ dispõe de forma clara que a ordem econômica é fundada na valorização do trabalho, ou seja, só haverá um crescimento econômico sustentável quando for observada a valorização do trabalho, sendo que o referido dispositivo mostrou a preocupação com os direitos de terceira geração ao assegurar a todos a existência digna, conforme os ditames da justiça social, sendo que nos incisos VII e VIII ${ }^{14}$ determinou a observância dos princípios quanto à redução de desigualdades regionais e sociais e a busca do pleno emprego.

A mulher imigrante que estiver em condições análogas a de escravo ou qualquer trabalhador tem em nossa Constituição Federal, como em normas infraconstitucionais o respaldo necessário, sendo importante que todos aqueles que militam na seara do Direito estejam atentos a realidade do país e as nossas legislações, para que possa de fato haver justiça em nosso país.

Não é possível ainda dissociar o contido na Declaração Universal dos Direitos Humanos da ONU quanto norma garantidora de direitos humanos às mulheres refugiadas, já que protege o direito à vida, à liberdade e à segurança pessoal, e é mandatória quanto à proibição da escravidão ou servidão, e tráfico de escravos em toda as suas formas. Ainda prima pela liberdade de saída e reingresso em seu país de origem.

No mais, há de se verificar que o desenvolvimento econômico almejado por nossa Constituição deve ser lido nos moldes da Declaração Direito ao Desenvolvimento da ONU do ano de 1986, posto ser um processo econômico, social, cultural e político abrangente. Não podendo uma nação buscar o desenvolvimento sem respeito e meios de efetivação dos direitos humanos dos trabalhadores imigrantes.

Reconhecendo que o desenvolvimento é um processo econômico, social, cultural e político abrangente, que visa ao constante incremento do bem-estar de toda a população e de todos os indivíduos com base em sua participação ativa, livre e significativa no desenvolvimento e na distribuição justa dos benefícios daí resultantes;

\footnotetext{
${ }^{13}$ Art. 170. A ordem econômica, fundada na valorização do trabalho humano e na livre iniciativa, tem por fim assegurar a todos existência digna, conforme os ditames da justiça social, observados os seguintes princípios:

${ }^{14}$ VII - redução das desigualdades regionais e sociais;

VIII - busca do pleno emprego;
} 
A Declaração e Programa de Ação de Viena no item cinco prevê que os direitos humanos são universais, indivisíveis, interdependentes e inter-relacionados, de modo que o homem é um ser biocultural, portanto, inseparável da própria substância humana, não podendo ser desconsiderado, devendo as imigrantes refugiadas no Brasil ter acesso, manutenção e respeito a sua dignidade considerando a sua cultura de origem inclusive.

No mais, temos a Lei $n^{\circ} 13.445 / 2017$, nova Lei de Migração, que prevê o visto de acolhida humanitária ao imigrante "em situação de grave ou iminente instabilidade institucional, de conflito armado, de calamidade de grande proporção, de desastre ambiental ou de grave violação de direitos humanos ou de direito internacional humanitário". Já a Lei no 9.474/1997 define os mecanismos para a implementação do Estatuto dos Refugiados, com os procedimentos de solicitação de refúgio e os direitos e deveres dos refugiados.

Outrossim, não apenas por força de normas internacionais, da Constituição Federal e leis próprias é que as normas trabalhistas devem ser aplicadas de forma equivalentes aos refugiados, mas inclusive por força da CLT que prevê a igualdade salarial e gênero.

Contudo, mesmo com vasto arcabouço jurídico protegendo as imigrantes mulheres no Brasil a realidade que temos essa parcela da população mais vulnerável à exploração, assédio moral e sexual, são expostas em maior número à solicitação de testes de gravidez préemprego, demitem por engravidar e assediam moral e sexualmente (BERRY; BELL, 2012).

Ainda, temos que mesmo as mulheres refugiadas tendo alta qualificação técnica por vezes são alocadas em subempregos ou em colocações inferiores a sua capacidade, com menores salários, ocupando por vezes, colocações em condições precárias, que não despertam tanto interesse dos nativos (BAUMAN, 2017).

A questão segundo BOBBIO (1992, p.25) quanto aos direitos humanos dos refugiados "não é mais a de fundamentá-lo, mas sim de protegê-lo".

Para colocar em prática a proteção aos direitos humanos das mulheres refugiadas considerando sua colocação no mercado de trabalho de forma digna é possível se utilizar da mesma proposição utilizada por UNZUETA (1997. p.118) ao tratar de equidade de gênero no sentido de que temos a constatação da desigualdade entre homens e mulheres, mas a forma de 
"superar" esse ponto de partida é diferente: promovendo a igualdade (para o futuro), ou corrigindo (ou compensando) a desigualdade (no presente).

A questão de diferenciação de gênero entre nacionais é campo que se pode dizer violadora dos direitos humanos trabalhistas das mulheres de forma geral ante a constatação de menores salários destinados às mulheres, cargos mais elevados destinados a homens, entre outros fatos, o que tende a agravar a situação se considerarmos outras peculiaridades da mulher trabalhadora, se negra, se indígena, se estrangeira, e ainda se refugiada ante o preconceito existente e discriminação.

Com a finalidade de promover a igualdade para o futuro como leciona Unzueta há a possibilidade de utilização de mecanismos de educação para o mercado de trabalho destinado a cursos de inclusão, códigos de éticas eficazes, a participação das grandes empresas do Pacto Global, o uso do compliance, e outros tantos métodos.

Contudo, o respeito aos direitos humanos dessa população não pode aguardar anos para que haja espécie de inconsciente coletivo antidiscriminação, seus direitos são violados a cada dia, de modo que se faz necessário utilizar do segundo método proposto por Unzueta para assim corrigir ou compensar a desigualdade no presente.

Para tal intento é possível se utilizar de dois mecanismos o poder punitivo do Estado ou criação de políticas inclusivas por meio de cotas ou programas especiais às mulheres refugiadas.

Quanto às cotas temos no Brasil alguns projetos de lei tramitando que tentam a inclusão no sistema trabalhista público e privado às mulheres independente da origem, podemos citar o PL 4020/2019 que prevê cotas de 30\% mulheres acima de 40 anos em concurso público; o PL 3510/2020 com cotas de $15 \%$ mulheres em concurso público; o Projeto de Lei do Senado (PLS) 216/2016, com a reserva de 30\% das vagas nas empresas privadas para mulheres; e o Projeto de Lei 785/21 criando cota obrigatória mínima de 30\% de participação de mulheres em conselhos de administração de companhias abertas, de empresas públicas, de sociedades de economia mista, de suas subsidiárias e controladas, e outras companhias em que a União, direta ou indiretamente, detenha a maioria do capital social com direito a voto. 
Devido ao processo legislativo não ser breve no Brasil temos que na prática a hipótese das cotas para mulheres em geral que ante a igualdade de nossa Constituição Federal pode ser lida também aplicável às mulheres imigrantes acaba não sendo auto-aplicável corrigindo a violação aos direitos humanos das mesmas.

Restando assim a possibilidade de utilização de programas especiais de inclusão ao trabalho digno às mulheres refugiadas, papel esse que vem sendo exercido atualmente no Brasil por diversas ONGs.

Quanto ao último mecanismo possível para garantia dos direitos humanos às mulheres refugiadas na esfera laboral vem a ser a utilização do poder punitivo e repressivo do Estado, que em se tratando de ações individuais depende de provocação da própria parte, o que por vezes acaba não sendo acessível às trabalhadoras refugiadas posto que muitas delas não estão no país de forma regular.

No tocante as ações coletivas o órgão atuante no desrespeito aos direitos humanos trabalhistas das refugiadas vem a ser o Ministério Público do Trabalho ou Ministério Público Federal nos moldes do preceituado na CF/88 art. 127. Há também a atuação da Polícia Federal, fiscais do trabalho, e o próprio Poder Judiciário.

Desse modo, como leciona PIOVESAN (2011, p. 56) para efetivação dos direitos humanos se faz necessária a criação de ações específicas dirigidas a determinado grupo ante a indivisibilidade dos direitos.

A efetiva proteção dos direitos humanos demanda não apenas políticas universalistas, mas específicas, endereçadas a grupos sociais vulneráveis, enquanto vítimas preferenciais da exclusão. Isto é, a implementação dos direitos humanos requer a universalidade e a indivisibilidade desses direitos, acrescidas do valor da diversidade.

No mais, a questão das mulheres refugiadas e a precariedade das relações de trabalho que as absorve derivam inclusive de outras práticas e pode incorrer em condutas delitivas como o tráfico internacional de pessoas; trabalho análogo a escravo; entre outras condutas, o que merece maior análise e repressão Estatal já que por ser a mulher refugiada imigrante grupo de maior vulnerabilidade social acaba sendo alvos mais fáceis de tais crimes e desrespeito a sua dignidade por consequência. 


\section{TRÁFICO DE PESSOAS E AS TRABALHADORAS REFUGIADAS.}

O tráfico de pessoas ocorre há muitos anos no mundo e com diversos escopos desde a exploração sexual, venda de órgãos, trabalho análogo a condição de escravo, e laboral em geral. Não podemos ainda deixar de destacar que países como a Síria, Iraque, e atualmente o Afeganistão, bem como vários outros são os que mais possuem refugiados pelo mundo, ante a crise humanitária que enfrentam em seu próprio país.

Assim, as pessoas que mais sofrem a violação aos direitos humanos decorrente do tráfico de pessoas são as mais vulneráveis e neste grupo encontramos as mulheres que buscam refúgio. Em âmbito internacional temos o Protocolo de Palermo que é marco legal de suma importância para o tema, que instituiu a definição de tráfico de pessoas, e o enquadramento dos traficantes, vide capítulo I, artigo $3^{\circ}$, alínea "a":

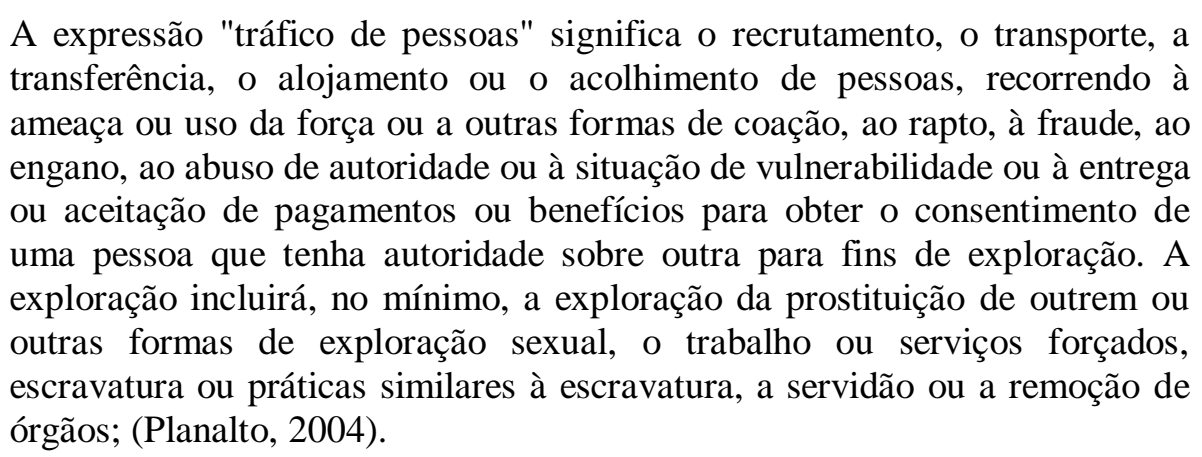

Logo, temos com clareza as situações que se encontram enquadradas como vítimas e como traficantes sendo que referido Protocolo foi ratificado pelo Brasil em 2004.

Ainda que não o fosse, por força na essência de nossa Constituição Social e humanista, não poderia o Brasil admitir em seu solo tais práticas, de modo que não por outra razão, ainda que tardiamente, foi publicada a lei $n^{\circ} 13.344 / 16$, que trata da prevenção e a repressão desse delito, bem como dá atenção às suas vítimas, bem como realizou a inclusão do artigo 149 - A do Código Penal ${ }^{15}$.

\footnotetext{
15 "Tráfico de Pessoas ameaça, violência, coação, fraude ou abuso, com a finalidade de:

I - remover-lhe órgãos, tecidos ou partes do corpo;

II - submetê-la a trabalho em condições análogas à de escravo;
}

Art. 149-A. Agenciar, aliciar, recrutar, transportar, transferir, comprar, alojar ou acolher pessoa, mediante grave 
Crítica geralmente feita à referida legislação brasileira vem a ser a tipificação restrita e fechada já que é bastante restritiva por reconhecer a vítima de tráfico de pessoas apenas na ocorrência da finalidade de remoção de órgãos, condições de trabalho análogas à escravidão, servidão, adoção ilegal ou exploração sexual, sendo que a União Européia possui rol mais amplo embarcando qualquer conduta ilícita como finalidade.

Outra crítica que vem sendo feita se dirige a causa de diminuição de pena ante a gravidade do crime e o fato de não estar o crime de tráfico de pessoas inserido no rol de equiparados a crimes hediondos.

Não podemos ainda deixar de mencionar o último Relatório Global sobre Tráfico de Pessoas do UNODC (Escritório das Nações Unidas sobre Drogas e Crime) $2020^{16}$, que trouxe como dados que as mulheres e meninas seguem sendo as principais vítimas do tráfico de pessoas na razão de $65 \%$ considerando o globo, bem como a ocorrência deste crime tendo por base a vulnerabilidade econômica das vítimas na razão de $51 \%$ ocorrendo não apenas com a finalidade de exploração laboral, mas em todas as suas vertentes (sexual, laboral, servidão, venda de órgãos, adoção ilegal).

Contudo, embora estejamos tratando do crime do tráfico de pessoas em especial das mulheres considerando a finalidade de exploração laboral não é possível dissociar geralmente a ocorrência conjunta da violência sexual sofrida pelas mulheres usada como coerção e/ou controle, o que ocorre inclusive pelo fato da simbiose local de exploração laboral moradia precária em mesmo ambiente destinada às vítimas.

Em grandes centros urbanos, como em São Paulo é fácil observarmos seja em matérias publicadas pela mídia, como na análise de decisões judiciais e em doutrinas a

III - submetê-la a qualquer tipo de servidão;

IV - adoção ilegal; ou

V - exploração sexual.

Pena - reclusão, de 4 (quatro) a 8 (oito) anos, e multa.

$\S 1^{\circ}$ A pena é aumentada de um terço até a metade se:

I - o crime for cometido por funcionário público no exercício de suas funções ou a pretexto de exercê-las;

II - o crime for cometido contra criança, adolescente ou pessoa idosa ou com deficiência;

III - o agente se prevalecer de relações de parentesco, domésticas, de coabitação, de hospitalidade, de dependência econômica, de autoridade ou de superioridade hierárquica inerente ao exercício de emprego, cargo ou função; ou

IV - a vítima do tráfico de pessoas for retirada do território nacional.

$\S 2^{\circ}$ A pena é reduzida de um a dois terços se o agente for primário e não integrar organização criminosa.

${ }^{16}$ UNODC. Global Report on Trafficking in Persons 2020. Vienna. 2021. 
exploração do trabalho dos imigrantes, principalmente da mulher imigrante e refugiadas em especial, nesta capital geralmente a exploração da mulher está relacionada considerando a exploração laboral às empresas de confecção que fornecem inclusive para grandes empresas da moda transnacionais, enquanto que no trabalho rural geralmente encontramos às mesmas no corte da cana, ou outra atividade agropecuária.

O fato de o globo ter vivenciado desde 2020 a crise sanitária e econômica decorrente da covid19 em um primeiro momento pode-se pensar que houve a diminuição da prática do tráfico de refugiadas até mesmo pela ocorrência de barreiras sanitárias entre os países, mas não se pode deixar de considerar que estamos diante de tipo penal, e por esta razão que não se utiliza dos meios legais para ingresso nos países na maioria das vezes.

Assim, em breve análise do impacto econômico considerando o crime de tráfico de pessoas no Brasil ante a covid19 pode se pensar que haverá o aumento da exploração de mulheres e meninas ante a grave crise econômica não apenas no Brasil, mas inclusive nos países de origem das referidas mulheres traficadas que saem em busca de refúgio. O mesmo para as mulheres brasileiras que acabam deixando o país em busca de melhores condições de vida em países mais desenvolvidos e também são vítimas do crime de tráfico de pessoas.

\section{FUNÇÃO SOCIAL DAS TRANSNACIONAIS NA INCLUSÃO DAS REFUGIADAS NO MERCADO DE TRABALHO.}

Nos moldes do manual para empresas multinacionais elaborado pela OCDE (Organização para a Cooperação e Desenvolvimento Econômico) no ano de 2000, o conceito de empresas transnacionais abarca sociedades ou outras entidades estabelecidas em mais de um país, ligadas umas nas outras e que conseguem coordenar suas operações de variadas formas.

Para Cretella Neto (2006, p. 302) a empresa transnacional é:

[...] aquela constituída segundo as leis de determinado Estado, na qual a propriedade é distinta da gestão, que exerce controle, acionário ou contratual, sobre uma ou mais organizações, todas atuando de forma concertada, sendo a finalidade de lucro perseguida mediante atividade fabril e/ou comercial em dois ou mais países, adotando estratégia de negócios 
centralmente elaborada e supervisionada, voltada para a otimização das oportunidades oferecidas pelos respectivos mercados internos.

Devido à magnitude de referidos conglomerados comerciais que muitas das vezes possuem PIB mais elevados que muitos países do globo é que se faz necessário que as mesmas adotem posturas de respeito aos direitos humanos trabalhistas das mulheres refugiadas já que além de possibilitarem a criação de disponibilização de postos de trabalho em número considerável ainda possuem o poder de influenciar positivamente ou negativamente empresas de todo o globo ante a globalização.

Assim, é preciso considerar a humanidade como um todo ante ao fenômeno da globalização como leciona IANNI (2000, p. 13):

[...] o globo não é mais exclusivamente um conglomerado de nações, sociedades nacionais, Estados-nações, em suas relações de interdependência, dependência, colonialismo, imperialismo, bilateralismo, multilateralismo. Ao mesmo tempo, o centro do mundo não é mais voltado só ao indivíduo, tomado singular e coletivamente como povo, classe, grupo, minoria, maioria, opinião pública. Ainda que a nação e o indivíduo continuem a ser muito reais, inquestionáveis e presentes todo o tempo, em todo lugar, povoando a reflexão e a imaginação, ainda assim já não são "hegemônicos". Foram subsumidos, real ou formalmente, pela sociedade global, pelas configurações e movimentos da globalização. A Terra mundializou-se de tal maneira que o globo deixou de ser uma figura astronômica para adquirir mais plenamente sua significação histórica.

Desse modo, é salutar que as empresas transnacionais não apenas não pratiquem tráfico de pessoas, e forneçam postos de trabalho para as mulheres refugiadas, mas que estes estejam em conformidade com a legislação trabalhista e principalmente de acordo com o respeito à dignidade da pessoa humana.

No mais, não podemos esquecer que é vigente no Brasil e em todo mundo a figura da terceirização e da aquisição de matérias primas de empresas parceiras e terceiras, de modo que as empresas transnacionais competem não apenas o respeito dentro de sua organização às mulheres trabalhadoras refugiadas, mas também em toda a sua cadeia de produção.

Tal respeito inclusive está intimamente ligado às boas práticas concorrenciais já que sabemos que a figura do dumping social muitas vezes é utilizada como meio de obter maior lucro em detrimento de outras empresas que respeitam os direitos humanos dentro de sua cadeia de produção. 
Sabedor de tal fato mesmo tendo havido no Brasil por força da lei 13.647/17 a figura da terceirização geral e irrestrita nos postos de trabalho para sua validade a empresa tomadora deve de fato contratar empresa idônea, o que importa também no respeito aos direitos humanos das mulheres imigrantes.

Referida flexibilização dos processos produtivos não ocorreu apenas no Brasil, mas em todo o globo conforme dispõe IANNI (2000, p. 56):

Com a nova divisão internacional do trabalho21, a flexibilização dos processos produtivos e outras manifestações do capitalismo em escala mundial, as empresas, corporações e conglomerados transnacionais adquirem preeminência sobre as economias nacionais. Elas se constituem nos agentes e produtos da internacionalização do capital. Tanto é assim que as transnacionais redesenham o mapa do mundo, em termos geoeconômicos e geopolíticos muitas vezes bem diferentes daqueles que haviam sido desenhados pelos mais fortes Estados nacionais.

Portanto, é importante que as empresas transnacionais assumam compromissos com os direitos humanos como ocorre com o Pacto Global da ONU, mas que de fato os coloquem em prática, já que é possível consultar empresas aderentes ao referido Pacto, que prima pelo respeito aos direitos humanos nas mais diversas vertentes, relacionadas em jurisprudências nacionais que em sua planta de produção ou ainda em empresas que fazem parte de sua cadeia produtiva utilizam-se de mão de obra advinda de trabalho análogo à escravo, e que geralmente envolve mulheres refugiadas.

No mais, é importante frisar que as normas da OIT não fazem diferença entre o trabalhador nacional e o estrangeiro, embora algumas ressaltem de forma específica que não deve haver distinção entre as duas categorias, e outras, sejam especificamente destinadas à proteção do estrangeiro (SÜSSEKIND, 2000, p. 361).

Desse modo, se faz premente o desenvolvimento econômico sustentável na esfera laboral que passa pelas empresas transnacionais nos moldes previstos por SEN (P.11-12) em que o desenvolvimento se faz com a remoção das principais fontes de privação de liberdade: pobreza e tirania, carência de oportunidades econômicas e destituição social sistemática, negligência dos serviços públicos e intolerância ou interferência excessiva de Estados repressivos. 
Logo, a função social da empresa transnacional depende também do respeito aos direitos humanos em toda sua cadeia produtiva inserindo as mulheres refugiadas em seus postos de trabalho sem discriminação, e não se utilizando do recurso de mão de obra barata em razão de sua vulnerabilidade, e PEREIRA (2019. p. 68) descreve a função social como sendo o dever das sociedades exercerem suas atividades visando o bem comum, sem praticar atos lesivos à coletividade.

Como descreve SAYEG e BALERA (2019. p. 59), já que a economia deve ser vista de forma humanista e a livre concorrência compatibilizada com os direitos humanos.

O fundamento constitucional da livre iniciativa é de ser compatibilizado com a dignidade geral da população como valor indissociável ao direito à vida, intrinsecamente ligada ao direito de buscar melhores condições de existência, voltando-se então, para a linha do direito econômico e para uma ordem social que necessariamente precisa ser efetivadora dos valores humanos, sob o risco de se afundar na fria estrutura do liberalismo econômico, e, consequentemente perpetuar a pobreza e as desigualdades, contra os objetivos fundamentais da República.

Logo, o capitalismo é imantado pela dignidade da pessoa humana e por este motivo rechaça a discriminação visa à função social da propriedade privada, a busca do pleno emprego e a função social do contrato.

Temos que a dignidade humana é o principal limitador das ações das transnacionais dentro de sua planta de trabalho e na sua cadeia produtiva como um todo, o que importa dizer que devem se preocupar com a inclusão social em todas as vertentes, em especial no tema aqui proposto ante a extrema vulnerabilidade da mulher refugiada.

\section{CONSIDERAÇÕES FINAIS.}

A vulnerabilidade social afeta a todos os cidadãos, empresas públicas e privadas, bem como a economia do país havendo afronta direta aos direitos humanos dessa parcela da população. 
O grau de vulnerabilidade aumenta ao tratarmos da mulher trabalhadora devido a questão de gênero, e se aprofunda ainda mais no caso das mulheres refugiadas em razão de sua origem étnica e principalmente por conta das próprias razões do refúgio

O Brasil possui diversos diplomas legais internos em especial a Constituição Federal que contempla a igualdade e o respeito a dignidade da pessoa humana, também temos farta legislação e normas internacionais visando a proteção da mulher refugiada, e forte repressão ao crime de tráfico de pessoas.

Contudo, temos que ainda se faz necessária a implementação de medidas e políticas públicas para de fato acolher as mulheres refugiadas no Brasil possibilitando trabalho digno livre de preconceitos e abusos.

Chegou o tempo em que as relações de trabalho e emprego em especial nas empresas transnacionais necessitam absorver a força de trabalho das mulheres refugiadas inclusive em sua cadeia de produção em condições de equidade.

Somente com a visão humanista da economia poderemos ter o respeito aos direitos humanos das trabalhadoras refugiadas em solo brasileiro.

Isso porque normas indicativas de direitos, protetivas e coercitivas o Brasil já possui sendo necessário o enquadramento do mercado de trabalho as mesmas.

\section{REFERÊNCIAS}

BAUMAN, Z. Estranhos à nossa porta. Rio de Janeiro: Zahar, 2017.

BAUMAN, Zygmunt. Globalização: as consequências humanas. Tradução de Marcus Penchel. Rio de Janeiro: Zahar, 1999.

BERRY, D. P.; BELL, M. P. „Expatriates ${ }^{\text {ee }}$ Gender, Race and Class Distinctions in International Management. Gender, Work and Organization, v. 19, n. 1, p. 10-28, jan. 2012.

BERTOLDO, Jaqueline. Migração com rosto feminino: múltiplas vulnerabilidades, trabalho doméstico e desafios de políticas e direitos. Revista Katálysis [online]. 2018, v. 21, n. 02 [Acessado 29 Setembro 2021] , pp. 313-323. Disponível em: <https://doi.org/10.1590/1982-02592018v21n2p313>. ISSN 19820259.https://doi.org/10.1590/1982-02592018v21n2p313. 
BOBBIO, Norberto. A era dos direitos. Tradução Carlos Nelson Coutinho. Rio de Janeiro: Elsevier, 1992.

CRETELLA NETO, José. Empresa transnacional e direito internacional: exame do tema à luz da globalização. Rio de Janeiro: Forense, 2006.

IANNI, Octávio. Teorias da globalização. $8^{\text {a }}$ Ed. Rio de Janeiro: Civilização Brasileira, 2000 .

PEREIRA, Henrique V; MAGALHÃES, Rodrigo A. A função social das sociedades transnacionais. IN Marcelo (coord.) A Sustentabilidade Da Relação Entre Empresas Transnacionais E Direitos Humanos. Curitiba: Editora CRV.

PIOVESAN, Flávia. Direito ao trabalho e a proteção dos direitos sociais nos planos internacional e constitucional. In PIOVESAN, Flávia; CARVALHO, Luciana Paula Vaz de. Direitos humanos e direito do trabalho. São Paulo: Atlas, 2010, p. 3-31.

Direitos Humanos e justiça internacional: um estudo comparativo dos sistemas regionais europeu, interamericano e africano, 2 ed. São Paulo: Saraiva, 2011.

Direitos humanos e o direito constitucional internacional, 6 ed. São Paulo: Max Limonad, 2004.

Saraiva, 2011.

Direitos humanos e o direito constitucional internacional, 12 ed. São Paulo:

SAYEG, Ricardo e BALERA, Wagner. Fator CapH - Capitalismo Humanista - A Dimensão Econômica dos Direitos Humanos. São Paulo: Max Limonad, 2019

SEN, Amartya. Desenvolvimento como liberdade. Companhia das Letras. Edição do Kindle.

SÜSSEKIND, Arnaldo. Direito internacional do trabalho, 3 ed. São Paulo: LTr, 2000.

UNODC. Global Report on Trafficking in Persons 2020. Vienna. 2021.

UNODC. How COVID-19 restrictions and the economic consequences are likely to impact migrant smuggling and cross-border trafficking in persons to Europe and North America. Vienna. 2020.

UNODC. Impacto da Pandemia COVID-19 no tráfico de pessoas. Conclusões preliminares e mensagens com base em um rápido balanço. Vienna. 2020a.

UNODC. Relatório Situacional Brasil. Tráfico de pessoas em fluxos migratórios mistos, em especial de venezuelanos. Brasília. $2020 \mathrm{~b}$.

UNODC. Documento temático. O abuso de posição de vulnerabilidade e "outros" meios no âmbito da definição do tráfico de pessoas. Vienna. 2012.

UNZUETA, Maria Angeles Barrère. Discriminación, Derecho antidiscriminatorio acción positiva en favor de las mujeres. Madrid: Cuadernos Civitas, 1997. (p.81-118) 